\title{
Desafios globais para o acesso equitativo à vacinação contra a COVID-19
}

\author{
Global challenges for equitable access to \\ COVID-19 vaccination
}

\author{
Desafíos globales para el acceso equitativo \\ a la vacunación contra la COVID-19
}

Luis Eugenio Portela Fernandes de Souza 1
Paulo Marchiori Buss 2

doi: 10.1590/0102-311X00056521
O rápido desenvolvimento de vacinas contra a COVID-19 representa um importante avanço da ciência e da saúde pública e alimenta a esperança de superação da pandemia. Contudo a aprovação de vacinas seguras e eficazes pelos órgãos reguladores é apenas um passo em uma longa caminhada até alcançar a imunidade coletiva capaz de propiciar o controle da doença.

O próximo passo é produzir doses suficientes de vacinas para alcançar uma cobertura que assegure a interrupção da transmissão comunitária. Trata-se de um grande desafio. Com efeito, inquérito conduzido em junho de 2020 pela Coalizão para Inovações em Preparação para Epidemias (CEPI - Coalition for Epidemic Preparedness Innovations) 1 estimou em 2 a 4 bilhões de doses a capacidade mundial de produção de vacinas contra COVID-19 até o fim de 2021. Quatro bilhões de doses seriam suficientes para vacinar cerca de $25 \%$ da população mundial, considerando duas doses por pessoa, como requer a maioria das vacinas aprovadas. Cobertura insuficiente para interromper a transmissão.

Alta prioridade, portanto, deve ser dada à ampliação da capacidade de produção. Para isso, a melhor estratégia seria generalizar os processos de transferência de tecnologia, permitindo que outros fabricantes, além dos detentores das patentes, dominassem a tecnologia e investissem na ampliação da produção. Há, contudo, um obstáculo maior a essa transferência: o regime de direitos de propriedade intelectual.

Nesse sentido, a principal iniciativa relativa à expansão da capacidade mundial de produção partiu da Índia e África do Sul, que propuseram ao Conselho TRIPs (Acordo sobre Aspectos dos Direitos de Propriedade Intelectual Relacionados ao Comércio) da Organização Mundial do Comércio (OMC) a suspensão temporária dos direitos de propriedade intelectual. Desde outubro de 2020, essa proposta vem sendo discutida 2, mas uma decisão favorável parece improvável, dada a oposição dos Estados Unidos, do Canadá, Reino Unido e da União Europeia. Registre-se que o Brasil também tem se posicionado contrário a essa suspensão.

Com uma oferta limitada de doses de vacinas, com reduzidas perspectivas de aumento da produção no curto prazo, os desafios, por conseguinte, são a distribuição e o acesso equitativo entre países e entre grupos populacionais.

No que tange aos países, aqueles de alta renda se anteciparam e fizeram acordos de compra antes mesmo da comprovação de segurança ou eficácia das vacinas. Até o dia 24 de fevereiro, 191 milhões de doses tinham sido administradas, das quais 75\% em apenas 10 países. Em 130 nações, com 2,5 bilhões
${ }^{1}$ Universidade Federal da Bahia, Salvador, Brasil. ${ }^{2}$ Centro de Relações Internacionais em Saúde, Fundação Oswaldo Cruz, Rio de Janeiro, Brasil.

\section{Correspondência}

L.E.P. F. Souza Universidade Federal da Bahia.

Rua Basílio da Gama s/n, Campus Universitário Canela, Salvador, BA 40140-060, Brasil. luiseugenio@ufba.br 
de habitantes, nenhuma dose foi aplicada. Os países ricos, que somam 16\% da população mundial, compraram mais da metade das doses disponíveis de vacinas contra COVID-19 3.

O diretor-geral da Organização Mundial da Saúde (OMS), Dr. Tedros Adhanom, criticou o "nacionalismo da vacina" - em que os países competem pelas doses disponíveis -, referindo-se a um "fracasso moral catastrófico" 4. No entanto a distribuição injusta das vacinas entre as nações não é apenas uma questão ética. Tratando-se de uma doença transmissível que não respeita fronteiras, a COVID-19 continuará a ser uma ameaça global enquanto existirem casos em qualquer parte do mundo, especialmente com o surgimento de novas variantes do SARS-CoV-2.

Para enfrentar a iniquidade na distribuição das vacinas entre os países, superando o sistema de alocação baseado no poder de compra de cada país, instituiu-se a COVID-19 Vaccine Global Access Facility - Covax, uma colaboração entre OMS, GAVI - The Vaccine Alliance e CEPI. Trata-se de iniciativa pela qual países de renda alta e média e organizações privadas financiam a compra de vacinas. As doses adquiridas são, então, distribuídas entre todos os países, mesmo os de baixa renda que não podem contribuir, em quantidades proporcionais às suas populações. A meta inicial é vacinar, com 1,8 bilhão de doses, $20 \%$ da população de cada país participante, incluindo aos 92 países de renda baixa até o fim de 20215.

Mesmo sendo uma iniciativa relevante, é preciso reconhecer que a meta está aquém das necessidades. Vacinar com uma dose $20 \%$ da população dos 165 países que aderiram à Covax não será suficiente para controlar a pandemia. Ainda assim, não será fácil alcançar essa meta.

As dificuldades da Covax começam com a insuficiência de recursos financeiros. Até 26 de fevereiro de 2021, os financiadores (governos e organizações filantrópicas) tinham se comprometido a doar USD 11 bilhões, o que deixava ainda um déficit de USD 22,2 bilhões para atingir a meta de 1,8 bilhão de doses. Ademais, existem incertezas, envolvendo questões relativas à capacidade de produção, regulamentação, formalização de contratos e preparação dos programas nacionais de vacinação nos diversos países 5 .

Além da distribuição equitativa em escala global, há o desafio do acesso desigual às vacinas entre os habitantes de cada país. Assim como os países de alta renda multiplicam as doses de vacinas para seus cidadãos, os indivíduos ricos de qualquer país podem usar seu poder de compra para obter acesso prioritário à vacinação.

Para evitar que isso aconteça, a maioria dos países tem organizado programas de vacinação em fases, conforme orientação da OMS 6, priorizando profissionais de saúde e pessoas com maior risco de doença grave ou morte por COVID-19, como idosos.

Todavia, mesmo com uma definição de prioridades, as desigualdades estruturais representam desafios para as populações em vulnerabilidade. Em áreas pobres ou distantes dos centros urbanos, por dificuldades logísticas e outras, a vacinação é mais lenta e alcança menor cobertura.

$\mathrm{Na}$ América Latina, que detém 26\% das mortes e 18\% dos casos da COVID-19 no mundo, foram aplicadas apenas 6\% das vacinas 7 . Embora alguns países da região tenham começado, a vacinação segue a passos lentos, sem conseguir acompanhar o avanço da transmissão. Das 33 nações, 18 não começaram a imunizar a população. Desigualdade profunda no olho do furacão.

O Brasil, particularmente, por meio do Programa Nacional de Imunizações (PNI), tem alcançado elevadas coberturas vacinais, embora, desde 2016, as metas não estejam sendo atingidas 8 . Em entrevista à CNN, o ex-ministro José Gomes Temporão lembrou que, em 2010, no curto período de três meses, foram vacinadas 80 milhões de pessoas contra o H1N1 e que, em um único dia, o PNI consegue vacinar 10 milhões de crianças contra a poliomielite 9 . A princípio, portanto, o país reúne as condições técnicas para um programa eficiente e equitativo de vacinação contra a COVID-19. Assim, no Brasil, a dificuldade se atém à obtenção de doses de vacinas suficientes.

Nesse ponto, vale destacar as atuações da Fundação Oswaldo Cruz (Fiocruz) e do Instituto Butantã que, em parcerias com a AstraZeneca/Oxford University e com a Sinovac Biotech, respectivamente, têm assegurado aos brasileiros o acesso às vacinas. Com essas vacinas, o Brasil pode iniciar a vacinação, dando prioridade a trabalhadores de saúde, idosos, pessoas com deficiência institucionalizadas e povos indígenas. Até o dia 28 de fevereiro, haviam sido aplicadas 6,9 milhões de doses, correspondendo a 5,5 milhões de pessoas com a primeira dose e 1,4 milhão com a segunda dose (Ministério da Saúde. COVID-19, vacinação: doses aplicadas. https://qsprod.saude.gov.br/extensions/DEMAS_ C19Vacina/DEMAS_C19Vacina.html, acessado em 28/Fev/2020). 
A campanha de vacinação, no entanto, não tem tido o grau de organização que o PNI costumava imprimir a suas campanhas. Infelizmente, por atos e omissões, o governo brasileiro que, desde o início da pandemia, não tem tomado as medidas de controle da doença ou tem contribuído para seu agravamento 10, tampouco tem facilitado o desenrolar das ações de vacinação, atrasando a compra e a distribuição das vacinas e se negando a fazer campanhas de comunicação.

Como se isso fora pouco, o próprio presidente estimulou a criação de um consórcio de grandes corporações privadas nacionais para, com autorização do Ministério da Saúde, importar 33 milhões de doses de vacina, tendo enviado, na última semana de janeiro, carta à AstraZeneca, informando essa decisão 11. No início de janeiro, a Associação Brasileira de Clínicas de Vacinas já tinha anunciado a compra de 5 milhões de doses da vacina Covaxin, do laboratório indiano Bharat Biotech, com o objetivo de vacinar parte da população que não está nos grupos prioritários 13 . Obviamente, a disponibilização de vacinas pela rede privada ampliará ainda mais as desigualdades entre brasileiros de maior e menor poder econômico.

Enfim, são enormes os desafios do acesso equitativo à vacinação contra a COVID-19, envolvendo desde a produção de doses em quantidade suficiente até a organização de programas eficientes de vacinação, passando pela garantia de uma distribuição que obedeça a critérios éticos e epidemiológicos.

No plano global, a menos que os governos dos países de alta renda e a indústria farmacêutica modifiquem seus comportamentos e tomem medidas urgentes para garantir que doses suficientes da vacina COVID-19 sejam produzidas e distribuídas de forma equitativa, não haverá ética e justiça nas relações entre os povos nem haverá controle efetivo da pandemia.

Além disso, sem uma distribuição equitativa das vacinas, a economia mundial não se recuperará, causando maior sofrimento humano e mais mortes evitáveis. Uma análise do Escritório Nacional de Pesquisa Econômica (Estados Unidos) estima que, se as pessoas nas nações ricas são vacinadas imediatamente, mas nas nações mais pobres somente nos próximos anos, a economia global encolherá em USD 9 trilhões 12.

Para proteger a vida das pessoas, uma imunização eficaz e segura contra a COVID-19 deve ser considerada um bem público global, e as vacinas devem ser produzidas em volumes maiores, distribuídas de acordo com critérios éticos e epidemiológicos e fornecidas sem nenhum custo para o usuário. Isso pode ser alcançado renunciando-se aos direitos de propriedade intelectual para vacinas contra a COVID-19, compartilhando abertamente a tecnologia das vacinas, financiando plenamente a Covax, interrompendo acordos bilaterais e investindo no fortalecimento dos sistemas nacionais de saúde. Trata-se, em última instância, de cumprir as obrigações com os direitos humanos, promovendo, ao invés de impedir, o acesso mundial à vacina.

No plano nacional, a sociedade brasileira precisa se decidir por enfrentar seriamente a pandemia. Estando mais que evidente a inépcia do Governo Federal, a Associação Brasileira de Saúde Coletiva (ABRASCO) propõe a organização de um "Comitê de Salvação Nacional", com a participação de representações das três esferas de governo (União, estados e municípios) e de representações do controle social do Sistema Único de Saúde (SUS) e da comunidade científica 13.

Numa análise de ordem estrutural, pode-se afirmar que a situação atual de crise da saúde global maximizou a tendência de concentração econômica e, portanto, a apropriação dos lucros, junto com a afirmação de uma lógica desigual de poder de cada Estado, evidenciando-se muito claramente as iniquidades que o capitalismo vem acelerando no seu atual estágio de desenvolvimento. Os grandes conglomerados econômicos da indústria farmacêutica concentram-se e lucram com a doença, protegidos e sustentados pelo peso econômico e político dos Estados-nação onde estão sediados. Esses Estados reafirmam o poder desigual de dominação internacional. Os laboratórios produzem no marco da globalização e são sustentados por facilidades e subsídios concedidos pelo poder dos principais países do capitalismo desenvolvido e mesmo organismos internacionais, que estimulam a liberalização sem freios, sem regulação e sem ética da economia mundial em geral e da saúde em particular.

Para concluir, vale dizer que a sociedade civil, no Brasil e no mundo, está ativa, pressionando governos e organismos multilaterais a adotarem as medidas necessárias para controlar a pandemia e tornar menos desiguais todas as sociedades. Um exemplo marcante tem sido dado pelo Sustainable Health Equity Movement (SHEM - Movimento de Equidade na Saúde Sustentável. https://www.sus tainablehealthequity.org/, acessado em 28/Fev/2021), que reúne entidades científicas e profissionais de todas as partes de mundo, fazendo investidas nos diversos organismos internacionais, como a 
Assembleia Geral, o Conselho de Direitos Humanos e o Conselho Econômico e Social das Nações Unidas, além de arranjos políticos como o G20, cobrando coerência pós-retórica dos seus membros em prol da equidade no acesso às vacinas e outros insumos destinados ao enfrentamento da pandemia.

Sem uma diplomacia da saúde eficaz para garantir acesso equitativo às vacinas, não haverá controle da pandemia nem recuperação econômica. Para que mudem de postura, é imprescindível que os países ricos e as classes dominantes não esqueçam que ninguém estará seguro, até que todos estejam seguros.

\section{Colaboradores}

L. E. P. F. Souza concebeu e redigiu o texto, aprovou a versão final e é responsável por todos os aspectos do trabalho. P. M. Buss concebeu e revisou criticamente o texto, aprovou a versão final e é responsável por todos os aspectos do trabalho.

\section{Informações adicionais}

ORCID: Luis Eugenio Portela Fernandes de Souza (0000-0002-3273-8873); Paulo Marchiori Buss (0000-0002-9944-9195).

\section{Referências}

1. Coalition for Epidemic Preparedness Innovations. CEPI survey assesses potential COVID-19 vaccine manufacturing capacity. https://cepi.net/news_cepi/cepi-survey-assess es-potential-covid-19-vaccine-manufacturingcapacity/ (acessado em 27/Fev/2021).

2. World Trade Organization. Members to continue discussion on proposal for temporary IP waiver in response to COVID-19. https:// www.wto.org/english/news_e/news20_e/trip_ 10dec20_e.htm (acessado em 27/Fev/2021).

3. Yamey G. Rich countries should tithe their vaccines. Nature 2021; 590:529.

4. Chefe da OMS alerta contra "fracasso moral" da vacinação contra Covid-19. ONU News 2021; 18 jan. https://news.un.org/pt/story/ 2021/01/1739022.

5. Coalition for Epidemic Preparedness Innovations; GAVI - The Vaccine Alliance; World Health Organziation. Covax global supply forecast January 20, 2021. https://www.gavi.org/ sites/default/files/covid/covax/COVAX\%20 Supply\%20Forecast.pdf (acessado em 27/ Fev/2021).

6. World Health Organization. Roadmap for prioritizing population groups for vaccines against covid-19. https://www.who.int/im munization/sage/meetings/2020/october/Ses sion03_Roadmap_Prioritization_Covid-19_ vaccine.pdf (acessado em 28/Fev/2021). 
7. América Latina só aplicou $6 \%$ das vacinas, mesmo tendo $26 \%$ das mortes por Covid. Saúde IG 2021; 28 fev. https://saude.ig.com.br/corona virus/2021-02-28/america-latina-so-aplicou6-das-vacinas-mesmo-tendo-26-das-mortespor-covid.html.

8. Lisboa V. Em queda há 5 anos, coberturas vacinais preocupam Ministério da Saúde. Agência Brasil 2020; 16 out. https://agenciabrasil.ebc. com.br/saude/noticia/2020-10/em-queda-ha5 -anos-coberturas-vacinais-preocupam-minis terio-da-saude.

9. Lara L. SUS é capaz de atender demanda por vacina, diz ex-ministro da Saúde. CNN Brasil 2021; 7 jan. https://www.cnnbrasil.com. $\mathrm{br} / \mathrm{saude} / 2021 / 01 / 07 / \mathrm{sus}$-e-capaz-de-aten der-demanda-por-vacina-diz-ex-ministro-dasaude.

10. Mafei R, Santos JV, Machado E. Denúncia com pedido de perda do cargo e de direitos políticos (impeachment). https://www.conjur.com.br/ dl/ex-ministro-saude-assina-pedido.pdf (acessado em 27/Fev/2021).
11. Governo Bolsonaro dá aval para compra privada de vacinas contra a COVID-19. Estado de Minas 2021; 26 jan. https://www.em.com.br/ app/noticia/nacional/2021/01/26/interna_na cional,1232318/governo-bolsonaro-da-avalpara-compra-privada-de-vacinas-contra-acovid-19.shtml.

12. National Bureau of Economic Research. The economic case for global vaccinations: an epidemiological model with international production networks. (Working Paper, 28,395). https://www.nber.org/papers/w28395 (acessado em 28/Fev/2021).

13. Associação Brasileira de Saúde Coletiva. Salvar vidas urgentemente! https://www.abrasco.org. $\mathrm{br} / \mathrm{site} /$ noticias/especial-coronavirus/salvarvidas-urgentemente/56387/ (acessado em 28/ Fev/2021). 